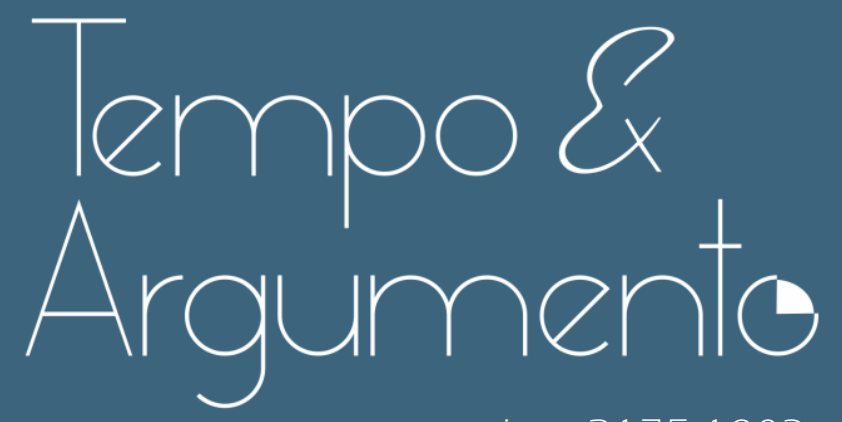

e-issn 2175-1803

Derivas subnacionales de la Multipartidaria: activación política y consensos sociales en la transición a la democracia (La Pampa, Argentina, 1981-19831

- Marisa Alejandra Moroni

Doctora en Historia por la Universidad de Sevilla (US). Investigadora del Consejo Nacional de Investigaciones Científicas y Técnicas de Argentina (CONICET) Instituto de Estudios Históricos y Sociales de La Pampa (IEHSOLP). Profesora en la Universidad Nacional de La Pampa, Argentina (UNLPam).

Santa Rosa - ARGENTINA

muw.conicet.gov.ar/

marisa.a.moroni@gmail.com

(iD) orcid.org/0000-0002-8311-2512

Para citar este articulo:

MORONI, Marisa Alejandra. Derivas subnacionales de la Multipartidaria:

activación política y consensos sociales en la transición a la democracia (La

Pampa, Argentina, 1981-1983). Tempo e Argumento, Florianópolis, v. 12, n.

29, e0206, jan./abr. 2020.

(d)

http://dx.doi.org/10.5965/2175180312292020e0206

Recebido: 09/05/2019

Aprovado: 19/09/2019 


\title{
Derivas subnacionales de la Multipartidaria: activación política y consensos sociales en la transición a la democracia (La Pampa, Argentina, 1981-1983)
}

\begin{abstract}
Resumen
En un clima de cuestionamientos internos y frágiles acuerdos sectoriales en las Fuerzas Armadas, a fines de marzo de 1981, asumía el segundo presidente de facto en Argentina, el general Roberto Viola, representante del Ejército en la sucesión política del régimen militar. Su gestión prefiguraba el ascenso de la denominada "línea política", sin embargo, su breve estancia al frente del Poder Ejecutivo adelantaba la complejidad para debatir acerca del statu quo del Estado autoritario sin confrontar con los sectores militares ortodoxos que, finalmente, provocarían su alejamiento del poder. Durante el mandato de Viola, se ensayaron una serie de estrategias destinadas a controlar el proceso de deslegitimación de la dictadura y contener las expectativas de distintos sectores sobre el futuro escenario político nacional. En esa línea, se incrementó la inclusión de actores civiles en los elencos de gobierno nacional y provincial, sin que ello implicara ceder el control del juego político o establecer plazos electorales. En contrapartida, la dirigencia política se reunía en una Comisión Multipartidaria para negociar el levantamiento de la veda política y definir el carácter que adoptaría la normalización institucional. En este artículo, examinamos las características del proceso de activación política desde un escenario subnacional, con el objetivo de identificar la modalidad de intervención de los actores políticos civiles en los encuentros multipartidarios durante la transición a la democracia en Argentina.
\end{abstract}

Palabras clave: Historia Reciente. Dictadura. Militares. Partidos Políticos. Democracia.

\section{Subnational drifts of the Multiparty Commission: political activation and social consensuses in the transition to democracy (La Pampa, Argentina, 1981-1983)}

\begin{abstract}
In an atmosphere of internal doubts and weak sectoral agreements in the Armed Forces, at the end of March 1981, the second de facto president took office in Argentina, General Roberto Viola, representing the Army in the political succession of the military regime. His administration foreshadowed the rise of the so-called 'political line,' however, his brief stay at the head of the Executive Power anticipated the complexity of debating the status quo of the authoritarian State without challenging the orthodox military sectors that, in the end, would lead to his estrangement from power. During Viola's administration, a series of strategies aimed to exercise control over the process of delegitimizing the dictatorship and to hold back the expectations of various sectors about the future national political scenario. On that line, the inclusion of civilian players into the national and provincial government teams increased, and this did not mean giving up control of the political game or establishing electoral deadlines. In counterpart, the political leadership met in a Multiparty Commission to negotiate an end to political closure and to define the nature that institutional standardization would take. In this article, we analyze the features of the political activation process from the perspective of a subnational scenario, in order to identify the intervention mode of civilian political players in multiparty meetings during the transition to democracy in Argentina.
\end{abstract}

Keywords: Recent History. Dictatorship. Military Men. Political Parties. Democracy.

\footnotetext{
Este artículo se desarrolló en el marco de las actividades de la Red de Estudios Sociohistóricos sobre la Democracia (RESHIDE) y del proyecto de investigación "Transición democrática y construcción política en las provincias de La Pampa, Neuquén y Chubut”, radicado en la Facultad de Ciencias Humanas de la Universidad Nacional de La Pampa (UNLPam). Agradezco los comentarios de los evaluadores anónimos de la revista que contribuyeron al resultado final del trabajo.
} 


\section{Introducción}

En las últimas décadas, las investigaciones realizadas desde las ciencias sociales retomaron la complejidad del proceso político que siguió al período final de la dictadura y se ocuparon de definir los modos y tiempos de la denominada etapa de transición a la democracia en Argentina (CANELO, 2006; LVOVICH, 2009; MAZZEI, 2011; ÁGUILA; ALONSO, 2013; FELD; FRANCO, 2015; FRANCO, 2017, 2018a). En esa línea, el desarrollo que experimentó la historia reciente estuvo acompañado por la renovación de hipótesis y discusiones historiográficas vinculadas al impacto del pasado autoritario en el diseño y la estabilidad del nuevo gobierno constitucional (GARGARELLA; MURILLO; PECHENY, 2010; BOHOSLAVSKY, 2016; CANELO; FRANCO; MANZANO, 2016). Como hemos referido en otros trabajos, el surgimiento de políticas estatales y un importante consenso social propició la recuperación de material documental y de testimonios fundamentales para la conformación de archivos vinculados al pasado reciente y a temáticas asociadas a los Derechos Humanos (MORONI, 2019). Sin lugar a dudas, estas condiciones enriquecieron las agendas nacionales de investigación y, a un ritmo más lento, se incorporaron los análisis enfocados en las particularidades o regularidades de la cultura política en contextos provinciales (FAVARO; IUORNO, 2010; BEHREND, 2011; CAMINO VELA, 2012; FERRARI; GORDILLO, 2015; FERRARI; MELLADO, 2016; SCATIZZA, 2016; MORONI, 2019; CAMINO VELA; CARRIZO; MORONI, 2019). En este camino, se desarrollaron investigaciones referidas al reacomodamiento político en las jurisdicciones provinciales y a la forma en que las dirigencias irrumpieron en distintos niveles de poder en el diseño represivo del órgano máximo del gobierno de facto: la Junta Militar (LVOVICH, 2010; CANELO, 2011). En línea con otros estudios, sostenemos que ampliar la perspectiva de análisis y enfocarnos en la etapa que precedió la derrota de Malvinas en 1982 posibilitará una mayor comprensión de las estrategias de distintos actores políticos y sociales que colocaron en el debate público no solo la necesidad de revisar el rumbo económico del gobierno de facto, sino de exigir pautas para la normalización institucional, aunque, estos cuestionamientos no incluyeron cuestiones vinculadas a la situación de los Derechos Humanos y la revisión de la lucha antisubversiva (FRANCO, 2018b). La dimensión criminal de la represión no resultaba desconocida para los actores políticos y civiles, sin embargo, sus intervenciones se ajustaron a una realidad 
social donde la responsabilidad y la condena sobre el poder militar se incorporaban progresivamente en la agenda pública de los 1980. La estimación de riesgos y beneficios en relación a los aspectos controvertidos del autodenominado Proceso de Reorganización Nacional no estaba alejada de las opciones que poseían los partidos políticos y sus dirigentes a la hora de evaluar su papel en el futuro sistema político democrático y desempeñarse como intermediarios que podían disputar al Estado autoritario el monopolio de la política (QUIROGA, 2005). Al momento de trasladar la atención a los espacios provinciales, específicamente a la provincia de La Pampa, identificamos las derivas ilegales del poder autoritario y la represión a través de las publicaciones en la prensa local en una fecha temprana como fue 1980, sin embargo, las referencias específicas y menos indulgentes de la dirigencia política sobre la gestión del gobernador civil designado por los militares solo se concretaron a finales de 1981 y como resultado de las contradicciones en el poder castrense acerca de la salida política (MORONI, 2019). En el mes de julio de ese mismo año, en el contexto nacional se formalizaba un frente multisectorial que posteriormente se conocería como la "Multipartidaria”. Los mediadores políticos que la integraban se ocupaban de instalar en la opinión pública la discusión sobre los tiempos y los modos de la recomposición política, aunque eludían forzar algún tipo de acuerdo o pronunciamiento antiautoritario (QUIROGA, 2004; VELÁZQUEZ RAMÍREZ, 2015).

Desde una perspectiva analítica que atiende la escala subnacional de la política (BEHREND, 2011), en este artículo examinamos el papel que desempeñaron los actores políticos civiles en la construcción de poder posdictatorial en la provincia de La Pampa a partir de su intervención en la Comisión Multipartidaria. La investigación se nutrió de bibliografía especializada en el tema y la base documental se conformó a partir del relevamiento de fuentes periodísticas; de la documentación y las publicaciones internas de los partidos políticos; y de los testimonios de los protagonistas del proceso multipartidario que brindaron un rico panorama sobre las modalidades y estrategias en juego entre 1981 y $1983^{2}$.

\footnotetext{
${ }^{2}$ Desde una escala regional y en clave microanalítica, en este artículo se profundizan los aspectos referidos a la Multipartidaria abordados en una versión preliminar en Moroni (2019).
} 


\section{Una concertación de partidos políticos en un escenario dictatorial}

El nombramiento del segundo presidente de facto de la dictadura, el general Roberto Violaª alentó las expectativas de algunos sectores civiles que, desde finales de 1980, exigían la normalización institucional. Al mismo tiempo, los enunciados militares evidenciaban las diferencias en el interior de las fuerzas castrenses acerca del marco de legalidad en un posible escenario de apertura política monitoreado por la Junta Militar. Desde el inicio del gobierno de Viola, un importante frente de disputa de su gestión fue el rumbo económico y, en esa dirección, deben leerse los movimientos estratégicos en la cartera de economía (DAMILL, 2005). El desplazamiento del paradigmático ministro de economía José Martínez de Hoz, que permaneció durante los 5 años de la presidencia de facto del general Rafael Videla, procuraba revertir los cuestionamientos y las críticas tanto del sector castrense como de parte del arco político. Sin embargo, ello no significa que debemos abonar una "interpretación economicista" que posiciona a la clave económica como matriz interpretativa central y absoluta del proceso dictatorial (CANELO, 2016). Sin lugar a dudas, los efectos negativos de un proyecto económico que trastocó la estructura socioeconómica amplificaron las dificultades para construir consensos internos en las fuerzas militares y debilitó las iniciativas dialoguistas del denominado sector politicista de la dictadura. A pesar de ello, el gobierno de facto ratificaba la necesidad de un nuevo espacio de convergencia cívico-militar y en julio de 1981 convocaba al segundo Dialogo Político. Una instancia que ratificaba el marcado papel intervencionista que se autoasignaban las Fuerzas Armadas en el sistema político nacional y en el establecimiento de normas para regular el funcionamiento de los partidos (GONZÁLEZ BOMBAL, 1991). Al igual que en la primera etapa dialoguista formalizada marzo de 1980, la nueva convocatoria de 1981 acentuó las diferencias entre las líneas internas castrenses y la imposibilidad de los militares para conducir la normalización institucional sin atender las demandas de distintos actores políticos civiles (FRANCO, 2018d).

\footnotetext{
3 La Junta Militar de este nuevo período inaugurado en 1981 quedaba integrada por Fortunato Galtieri, general del Ejército, por el almirante Armando Lambruschini y por el brigadier de la Fuerza Aérea, Omar Graffigna.
} 
El progresivo deterioro de los acuerdos políticos e ideológicos de la Junta Militar horadó el discurso moralizador y la proyección del Plan Político ${ }^{4}$ del gobierno de facto. En este delicado equilibrio entre el "inmovilismo" y las pretensiones de continuidad que rodeaban al gobierno de facto, algunas fuerzas políticas comenzaron a alentar la reestructuración partidaria. Se trataba de una reacción que fue precedida por el accionar de los movimientos por los Derechos Humanos, por militantes y familiares de desaparecidos que ganaron las calles a partir de manifestaciones populares, de peregrinar en sedes judiciales y policiales y de publicar solicitadas en la prensa para exteriorizar una realidad que una parte de la sociedad prefería eludir o enmascarar bajo la denominada lucha contra la subversión. En este contexto y, en forma paralela al segundo momento dialoguista que convocaba el ministro del Interior de la dictadura, los dirigentes políticos lanzaban una propuesta multisectorial opositora que apuntaba a reunir a los partidos políticos y al sindicalismo para acordar un piso de coincidencias básicas y diseñar un cronograma con plazos de retorno al Estado de derecho. La relevancia institucional de la convocatoria lograba exonerar una narrativa exculpatoria y panegírica con la que se identificaban algunos sectores políticos para legitimar la actuación del régimen militar. Sin embargo, en esta primera instancia multisectorial no existió un posicionamiento directo sobre las denuncias de los desaparecidos, hubo que esperar a finales de 1982 para asistir a un giro frontal materializado en la convocatoria a una "Marcha por la Vida" con participación de los frentes político, sindical y estudiantil (CANELO, 2016).

La concertación política logró congregar a la mayor parte del arco partidario nacional: la Unión Cívica Radical (UCR), el Partido Justicialista (PJ), el Partido Demócrata Cristiano (PDC), el Partido Intransigente (PI), y el Movimiento de Integración y Desarrollo (MID). Esta conformación de un frente partidario de representación ampliada fue un importante precedente para la activación política. Como sostienen distintos autores, los integrantes de la Multipartidaria establecieron formalmente el inicio de la denominada transición a la democracia en un contexto político y social controlado por los militares y donde su poder

\footnotetext{
“ En relación al Plan Político de la dictadura, remitimos al estudio de Canelo (2016), que visibiliza los objetivos políticos del Proceso y al papel de las "usinas" para ponerlo en práctica. Este abordaje posibilita identificar los vínculos entre las Fuerzas Armadas y la política.
} 
subyacía como una realidad inmanente (FRANCO, 2018c, p. 113). Una de las consecuencias del consenso partidario que posibilitó poner en cuestión las opciones que postulaba el régimen militar para la sucesión política fue la activación del debate público y la reorganización interna de los partidos políticos en las jurisdicciones provinciales. En un clima de ficticia distención y apertura, los actores políticos, sindicales y estudiantiles comenzaron a visibilizar sus acciones en los medios gráficos y con distintos formatos de escritura alentaron la discusión sobre el futuro gobierno constitucional.

El estudio de la dinámica política que rodeó a la concertación multipartidaria en la provincia de La Pampa 5 posibilitará reconocer las variadas formas en que algunos actores políticos civiles proyectaron la reorganización institucional y la intervención de los militares en el juego político en escenarios provinciales.

\section{Condicionantes y réplicas provinciales de la Multipartidaria nacional}

La noticia acerca de una convocatoria multipartidaria nacional dirigida a distintos sectores políticos, sociales y gremiales comenzaba a ocupar las portadas de los diarios de la provincia de La Pampa. En los primeros días de junio de 1981, los titulares anunciaban que se trataba de alcanzar acuerdos y posibilitar "las soluciones institucionales que reclama la República" (DIARIO LA REFORMA, 12 jun. 1981). Unas semanas más tarde se publicaba una declaración conjunta firmada por la UCR, el PJ, el PDC, el PI y el MID donde se anunciaba la necesidad de constituir un "Cabildo abierto multiplicado en cada población de la República" (DIARIO LA REFORMA, 14 jul. 1981). La réplica de los referentes partidarios provinciales no se demoraba y, al día siguiente, los pampeanos suscribían el primer documento nacional de la Junta Convocante de la Multipartidaria y la

\footnotetext{
5 Los territorios nacionales se conformaron a partir de la Ley No. 1532, de 1884, que establecía la forma de organización institucional y administrativa de los espacios ubicados fuera de los límites de las 14 provincias tradicionales. De esta forma, quedaron establecidos los territorios nacionales de Misiones, Chaco, Formosa, La Pampa, Neuquén, Río Negro, Chubut, Santa Cruz y Tierra del Fuego (RUFFINI, 2007). La provincialización se concreta en 1951 tras la ampliación de derechos políticos que promovió el peronismo. Ver estudios detallados sobre el territorio nacional de La Pampa y la posterior etapa provincial en Lluch y Di Liscia (2011) y Lluch y Salomón Tarquini (2014).
} 
prensa local reproducía la noticia en éstos términos: "damos por iniciada la etapa de transición hacia la democracia, objetivo que constituye nuestra decisión intransferible e irrevocable. Lo hacemos bajo el lema del Episcopado Argentino: la reconciliación nacional" (DIARIO LA REFORMA, 15 jul. 1981).

Los objetivos de la convocatoria multipartidaria nacional se daban a conocer el 28 de julio de 1981 y, ese mismo día, la dirigencia provincial anunciaba a la opinión pública el cariz que adoptarían las reuniones en La Pampa. Si bien adelantaban que su agenda primaria se orientaba a discutir "cuestiones generales", progresivamente, comenzarían a trabajar sobre los plazos de la normalización institucional, el levantamiento de la veda política y la adopción de políticas estatales para superar la crisis económica y productiva que atravesaba la provincia. Esta cuestión no fue menor puesto que, en sintonía con los vaivenes de la economía en el plano nacional, se trataba de una matriz productiva en caída libre.

La convocatoria provincial fue precedida por un encuentro de los dirigentes del PJ, del MID y de la UCR que acordaban un cronograma de funcionamiento y participación de los partidos que integrarían formalmente la Comisión Multipartidaria. Finalmente, el 3 de agosto de 1981, en la sede de la UCR se constituía oficialmente el órgano multipartidario provincial con los dirigentes políticos de los partidos antes mencionados y el Partido Comunista (PC) como integrante de las comisiones de debate. El Movimiento Federalista Pampeano (MoFePa $)^{6}$, un partido de origen provincial de raigambre federalista se despegaba de las reuniones formales y, en su lugar, los dirigentes mofepistas con mayor impronta en el partido articulaban contactos personales con los miembros plenos de la concertación para conocer el tenor de las discusiones y las decisiones adoptadas en los encuentros multipartidarios formales. Es posible que esta modalidad de participación no convencional respondiera a una actitud flexible del partido y coherente con su función de interlocutores de la dictadura,

\footnotetext{
- El MoFePa integraba la Confederación de 15 partidos denominada Fuerza Federalista Popular (FUFEPO) y se orientaba a la defensa de los intereses federalistas que, en líneas generales, estableció un asiduo contacto con las Fuerzas Armadas. Los partidos de esta fuerza integraron una comisión de enlace para discutir cuestiones asociadas al sistema político en la que participaron Horacio Guzmán, el dirigente pampeano Ismael Amit, Celestino Gelsi y Alfredo Vicchi (MANSILLA, 1983).
} 
vínculo que no fue excluyente de este partido provincial federalista, sino que reconoce otros actores políticos como los representantes nacionales de la línea balbinista de la UCR. Tanto los mofepistas como otros dirigentes políticos de centro y de derecha no ocultaron esta postura y, como sostiene el estudio de Canelo (2016) para el caso nacional, estos pequeños partidos y la UCR confirmaron esta alineación con el aporte de funcionarios y de asesores en las distintas reparticiones dependientes de la Secretaría de Presidencia del gobierno de facto. En el caso de la exclusión formal y pública del MoFePa de la concertación de partidos provinciales debemos encuadrarla en la posición que desempeñaba en el juego político nacional y, especialmente, como parte de la Fuerza Federalista Popular (FUFEPO), una coalición política a la que adherían y que les permitía acceder a los recursos estatales y ocupar cargos políticos en la provincia y en los municipios. El distanciamiento formal del MoFePa de la Multipartidaria consolidó una imagen pública del partido dentro del entramado político provincial que lo ubicaba como corriente política civil del Proceso y que por su orientación ideológica lograba ocupar esferas de poder provincial y nacional. Sin lugar a dudas, esta realidad se reflejaba en el nombramiento de funcionarios del partido en las intendencias y, en 1981, en la gobernación. Sin embargo, tanto la UCR como el PJ aportaron su cuota civil al Plan Político de la dictadura $y$, aunque en menor medida, detentaron una efectiva participación en el nivel municipal (CANELO, 2015).

En la segunda reunión multipartidaria, el PJ ofició como anfitrión y una de las mociones inaugurales fue la incorporación de la Federación Socialista Pampeana a la mesa directiva. De esta forma, los dirigentes provinciales se distanciaban de la actuación nacional que limitaba la intervención de esta fuerza política a comisiones de trabajo (DIARIO LA REFORMA, 18 ago. 1981). Seguidamente, el fondo de debate se orientó a la situación política, a los plazos de la restitución del Estado de derecho y a la incorporación de la Iglesia Católica a partir de la propuesta de un sector político del peronismo. El clima de discusión que caracterizó las primeras reuniones se reflejaba en la prensa pampeana que, además del registro cotidiano de las sesiones, publicaba editoriales, documentos y cartas de lectores firmadas por dirigentes políticos, sindicales y estudiantiles 
que referían al "momento histórico" que atravesaba el país y destacaban la adhesión de la mayor parte del arco partidario provincial. Así, por ejemplo, el PC difundía un comunicado que expresaba sus coincidencias con los objetivos de la concertación multipartidaria por considerarla "la única vía para lograr una solución democrática y progresista para la Patria" (DIARIO LA REFORMA, 20 ago. 1981). Una característica distintiva de una de las reuniones convocadas por la Federación Demócrata Cristiana fue su carácter abierto y ampliado a diversos sectores de la sociedad pampeana. Esta condición posibilitaría advertir la gravedad económica y social que atravesaba la provincia y el rumbo que orientó el debate se concentró en la necesidad de atender la realidad económica y productiva. Así la versión local de la concertación de partidos adoptaba un tinte localista vinculado con la crítica situación del sector industrial y agropecuario que trasladaba sus reclamos a las reuniones multisectoriales donde muchos de sus representantes registraban una doble representación, es decir, como integrantes de los partidos políticos y como productores rurales o con intereses en el rubro comercial.

El 22 de agosto, la Comisión de Enlace provincial, definida por la prensa como "la comisión de los 12" (DIARIO LA REFORMA, 25 ago. 1981) difundía un documento político ${ }^{7}$ que, en sintonía con un instrumento análogo que circulaba en la prensa nacional, procuraba responder "el por qué", "el quién" y "el para qué" de la convocatoria multipartidaria provincial. Además de socializar el contenido de los temas abordados, en los manifiestos se convocaba a las agrupaciones gremiales, culturales, deportivas y cooperativas. Un ejemplo de ello fue el Mensaje a la Juventud redactado en septiembre de 1981, dirigido a sumar a este sector y a descentralizar los encuentros para incorporar los intereses del interior provincial a la hora de proyectar la reorganización política (DIARIO LA REFORMA, 7 sep. 1981). Paulatinamente, distintos sectores sociales adhirieron a la convocatoria y, en los primeros días de 1982, los jóvenes vinculados al radicalismo, los socialistas populares, comunistas, intransigentes y los demócratas cristianos fijaban su posición política en un documento crítico sobre

\footnotetext{
La redacción de comunicados denominados por los propios autores documentos políticos resumían los puntos centrales del debate multipartidario y fue una modalidad organizativa que perduró hasta el final de los encuentros.
} 
la situación provincial y en acuerdo con los pronunciamientos multipartidarios. En la declaración pública exigían:

[...] levantamiento del estado de sitio; retorno al Estado de derecho con plena vigencia de la Constitución Nacional; normalización de la actividad política, gremial, empresaria, estudiantil y cultural; libertad de los detenidos políticos sin causa ni proceso y esclarecimiento de la situación de los desaparecidos; no al nuevo estatuto de los partidos políticos y plena vigencia del actual. No a los condicionamientos y restricciones de ninguna índole (DIARIO LA ARENA, 3 ene. 1982).

La participación de distintos actores sociales posibilitó que los comunicados elaborados en el contexto de la Multipartidaria adoptaran un tono cada vez más reivindicativo y condenatorio sobre el accionar de las fuerzas militares y se multiplicaron los reclamos sobre las denuncias de los desaparecidos y la necesidad de dar respuestas antes de la retirada del gobierno de facto. Este clima político contagiaba el espacio público y se replicaba en distintas localidades pampeanas donde se discutía la posibilidad de la renuncia del gobernador civil designado por el gobierno de facto por "no resultar garantía en el proceso de institucionalización”, según señalaba la prensa provincial. La demanda de elecciones simultáneas en todo el país y el cese de los funcionarios civiles de la dictadura fue un tópico que conectó a todos los actores que intervinieron en los encuentros multisectoriales y constituyó un argumento constante en la prédica y reivindicación de convocantes y asistentes.

Las disputas internas en las Fuerzas Armadas y el quiebre que significó la derrota en Malvinas desplazaron de la escena política nacional los objetivos iniciales de la concertación de partidos. El efecto devastador de la derrota obligó a las Fuerzas Armadas a concentrar su atención en evitar la atomización del poder y la defección de los socios político-civiles que ahora se sumaban a los reclamos de diversos sectores que exigían un balance de sus prácticas al frente del gobierno de facto y del fracaso de Malvinas.

En el plano provincial, el antecedente multipartidario fue uno de los actos más relevantes de movilización política y partidaria en tiempos dictatoriales y permitió visibilizar las representaciones e intervenciones de distintos actores políticos civiles durante los años previos a la apertura democrática. 1982 fue un 
año de importantes transformaciones en el espacio público pampeano y el corolario fue una impactante movilización social denominada "Marcha por la Democracia y la Reconstrucción Nacional" que, el 16 de diciembre de ese año, ocupaba las calles de la capital provincial. Los preparativos de la movilización se anunciaban en la prensa local:

Bajo el lema "no sea indiferente, exprese su protesta contra el régimen que los agobia”, se cumplirá frente al Teatro Español de esta ciudad, el acto que la Multipartidaria provincial ha convocado en consonancia por lo propio hecho por su par nacional. La concentración ha sido propuesta para las 20 hs y en su transcurso se leerá un documento elaborado por los partidos convocantes que ayer tuvieron una manifiesta adhesión de diversos sectores políticos, sindicales y empresariales de esta ciudad (DIARIO LA ARENA, 16 dic. 1982).

En consonancia con el clima reivindicativo, la UCR expresaba que la concentración popular se transformaría en "una bofetada para el proceso militar y sus asociados civiles [...] porque se reclamará allí la inmediata vuelta a la democracia” (DIARIO LA ARENA, 16 dic. 1982). Al día siguiente, los editoriales periodísticos destacaban la importante asistencia de pampeanos marchando por las calles del centro de la capital provincial. En pleno proceso dictatorial, unas 3 mil personas desafiaban la veda política y exhibían carteles con consignas vinculadas al esclarecimiento de la situación de los desaparecidos y presos políticos, a la incorporación de los empleados de distintas reparticiones públicas y voceaban cánticos y lemas vinculados a la retirada del ilegítimo gobierno tanto nacional como provincial.

El clima social y político bajo el régimen militar resultaba cada vez más complejo. Por un lado, la sociedad pampeana salía a las calles, los sectores políticos se reorganizaban y establecían alianzas partidarias (REVISTA UCR, Año 1, No. 2, nov. 1982). Por otro lado, las disidencias en el interior de las Fuerzas Armadas resultaban evidentes y el denominado problema de los desaparecidos se hacía presente en los encuentros, los debates o la posibilidad de acuerdo entre los actores políticos (FRANCO, 2015). En este contexto, en abril de 1983, el Proceso presentaba el Documento Final. Se trataba de un intento de cierre unilateral de la lucha contra la subversión que desembocaría en el anuncio de 
Reynaldo Bignone sobre la plena institucionalización del país para los próximos meses, la puesta en vigencia del nuevo estatuto de los partidos políticos y el establecimiento de la fecha para las próximas elecciones. La crítica social a la actuación militar o, como sostienen algunos autores, "la defección política", resultaba una modalidad de adaptación y reacomodamiento de los sectores que, desde el inicio, acompañaron al denominado Proceso de Reorganización Nacional (FRANCO, 2018b). Las reacciones de los partidos políticos fueron analizadas tempranamente y algunas investigaciones sostienen que, en el arco político argentino, existió una débil convicción democrática. En su lugar, un sector no menor especulaba acerca de la intervención de las Fuerzas Armadas como un instrumento efectivo en la lucha contra la subversión. Este argumento fue utilizado por los propios militares en las distintas etapas de la dictadura, durante los juicios a Junta militar que promovió el gobierno democrático de Raúl Alfonsín y en los procesos judiciales que se sustancian en la actualidad (LVOVICH, 2010).

Durante la activación política a la que hemos referido, las fuerzas partidarias se erigieron en un importante punto de encuentro para los sectores y actores en condiciones de reconfigurar la representación política que se avecinaba. En La Pampa, durante la etapa previa a 1981, la modalidad de los vínculos que los partidos políticos establecían con el poder militar estaba fuertemente asociada a la participación o al distanciamiento dentro de los elencos gubernamentales, tanto en el Poder Ejecutivo provincial como en las intendencias municipales.

\section{¿Opciones civiles y militares en sistema político provincial?}

En los primeros días de 1981, la prensa reproducía el anuncio del presidente de facto que establecía la incorporación gradual de gobernadores civiles en los Poderes Ejecutivos provinciales. La comunicación movilizaba al panorama político pampeano y parte de la dirigencia local se precipitaba al encuentro con el general Viola y el Ministro del Interior. Una de las primeras reacciones de la prensa la encabezaba el diario La Reforma, de General Pico, una de las principales ciudades del norte pampeano. El periódico organizaba una serie de entrevistas a representantes políticos, económicos y sociales con el objetivo de responder a 
la siguiente pregunta: “¿Quién cree usted que debe ser el gobernador?” Los primeros en acceder a la requisitoria fueron los dirigentes del partido radical que manifestaban "ojalá no sea un pampeano, porque si es un pampeano tendrá que saber que lo único legitimo para gobernarnos es que lo elija el pueblo" (DIARIO LA REFORMA, 27-28 ene. 1981). Las declaraciones partidarias exigían elegir libremente al gobernador, sin necesidad de ajustarse a la nómina de candidatos elaborada por el poder castrense y sus aliados civiles, de lo contrario, rechazarían cualquier tipo de juicio sobre los nombres que circulaban en el espacio público pampeano. Una de las manifestaciones más paradigmáticas y esperadas fue la del ex gobernador peronista Salvador Ananía, un importante dirigente que lideró el proceso de institucionalización y organización política en la etapa provincial. Ananía proponía como primera opción la continuidad del gobernador de facto y, en caso de que las condiciones impuestas por los militares obstruyeran esta posibilidad, anticipaba la conveniencia de un candidato civil apolítico y sin antecedentes en la provincia para evitar enfrentamientos con las fuerzas políticas con aspiraciones futuras. Se trataba de una posición compartida por otros sectores partidarios como el MID, donde el peso del argumento estaba en el desempeño positivo del gobernador y no en la situación política del país o el contexto autoritario que implicaba la continuidad del funcionario escogido por los militares. El ex mandatario peronista sintetizaba una lectura política que poseía gran parte de la dirigencia local y sostenía "no voy a defender al gobierno en el orden nacional [...] pero en el orden provincial podemos estar - y estamos - muy satisfechos los pampeanos" (DIARIO LA REFORMA, 29 ene. 1981). Finalmente, como preveían los círculos políticos locales, la designación del gobernador civil para La Pampa recaía sobre un hombre perteneciente a las filas del MoFePa y funcionario provincial del área económica del gobierno de facto. Las voces opositoras a esta designación, como la de los dirigentes del Partido Demócrata Cristiano rechazaban el reparto de cargos y señalaban que el manejo de la provincia respondía a lógicas tradicionales como si se tratara de "una gran estancia, con un dueño que sin serlo se maneja como tal" (DIARIO LA ARENA, 29 abr. 1981). Por su parte, el radicalismo, a partir de un comunicado oficial, ratificaba lo actuado por el Comité Nacional del partido y se sumaba a las demandas de reimplantación de la actividad partidaria y a la convocatoria a elecciones para 
votar autoridades provinciales y nacionales. Estas prácticas fueron predecesoras de una serie de iniciativas de movilización política y ciudadana cuya consagración se produce a fines de 1982, cuando se ocupaban las calles y la sociedad pampeana se mantenía movilizada y expectante ante la descomposición del régimen de facto. En esta línea debe leerse el proceso de reorganización partidario y la inauguración de nuevas sedes en el interior de la provincia que caracterizará a la UCR y a los demás partidos políticos con representación provincial.

El gobierno militar buscaba transformarse en un aliado de los actores políticos civiles y, como sostienen distintos estudios, esto daba espacio a las propuestas que consideraban posible una salida institucional que incluía las Fuerzas Armadas (FRANCO, 2018d). La práctica de aportar referentes políticos provinciales para integrar elencos gubernamentales de la dictadura da cuenta de las posibles lecturas que realizaban los partidos políticos ante una posible normalización democrática. La reedición de una alianza cívico-militar fue una de las vías posibles dentro del sistema de partidos en Argentina y la inclusión de los militares se legitimaba a partir de la actuación represiva militar en el marco del denominado "consenso antisubversivo" (YANNUZZI, 1999; VEZZETTI, 2002).

Las expectativas que generaba la proximidad de un escenario democrático estimulaban la reacción de la dirigencia política en La Pampa, que se reagrupaba para obturar la posibilidad de la designación de un candidato civil en la Gobernación. El poder castrense planificaba un horizonte político y una lógica de funcionamiento democrático que validaba su papel negociador, sin embargo, es preciso expresar que esta posición tampoco formaba parte de los cuestionamientos de la mayoría de los partidos políticos.

\section{Conclusiones}

En la etapa previa a la ruptura que significó la Guerra de Malvinas, los militares argentinos intentaron dirigir el proceso aperturista y se arrogaban un papel arbitral en la transición a la democracia. Como hemos visto, a partir del fracaso político del régimen militar y de la división interna entre los distintos sectores castrenses, los partidos políticos en el contexto nacional y en el 
provincial comenzaron a relacionarse con los titulares del gobierno de facto para sortear las limitaciones y establecer condiciones al proceso de democratización que se discutía en el escenario político entre 1981 y 1983. En este artículo, analizamos los últimos años del régimen militar en el poder y la vinculación con las fuerzas políticas que comenzaban a reorganizarse para intervenir en el juego político democrático en la provincia de La Pampa. En línea con los estudios referidos a los últimos años dictatoriales, sostenemos que es preciso atender a la conexión existente entre ambos períodos para comprender las distintas dimensiones y los significados de la descomposición progresiva del régimen militar y las lecturas que hicieron distintos actores políticos y sociales de este proceso histórico (VELÁZQUEZ RAMÍREZ, 2015).

Las perspectivas de un escenario democrático en La Pampa y las expectativas sobre el momento político nacional desde el contexto local estuvieron presentes en la mayor parte de las discusiones políticas, sin embargo, las relaciones de proximidad y vecindad entre civiles y militares fue una característica dominante que no contribuía a generar propuestas que excluyeran categóricamente al sector castrense de las propuestas de gobierno democrático. Sólo a finales de 1981 y, especialmente, tras la derrota de Malvinas, comenzaron a manifestarse referencias condenatorias puntuales sobre el encarcelamiento de dirigentes políticos y sindicales en La Pampa o las desapariciones de comprovincianos en otros puntos del país.

La reacción de los sectores políticos que evitaban pronunciarse sobre la nominación de un gobernador civil en el Poder Ejecutivo provincial e incluso los que postulaban la permanencia de los militares como un componente más del sistema político formaba parte de las variadas formas de legitimación de este tiempo histórico donde los límites para la incorporación de las Fuerzas Armadas en el futuro proyecto democrático se desdibujaban tanto en el caso provincial analizado como en el contexto nacional. 


\section{Referências}

ÁGUILA, Gabriela; ALONSO, Luciano (coord.). Procesos represivos y actitudes sociales. Entre la España franquista y las dictaduras del Cono Sur. Buenos Aires: Prometeo, 2013.

BEHREND, Jacqueline. Introducción: política subnacional y democracia. Revista SAAP, v. 5, n. 2, p. 249-260, 2011.

BOHOSLAVSKY, Ernesto. Cambios en la historiografía académica en Argentina (2001-2015). Historia da Historiografia: International Journal of Theory and History of Historiography, v. 20, p. 102-120, 2016.

CAMINO VELA, Francisco. El mundo de la política en la Patagonia norte. Neuquén: Educo, 2012.

CAMINO VELA, Francisco; CARRIZO, Gabriel; MORONI, Marisa A. (coord.). Las transiciones a la democracia en sus actores. Reflexiones desde la Patagonia. Rosario: Prohistoria, 2019.

CANELO, Paula. La descomposición del poder militar en la Argentina. Las Fuerzas Armadas durante las presidencias de Galtieri, Bignone y Alfonsin (19811987). In: PUCCIARELLI, Alfredo (coord.). Los años de Alfonsín. ¿El poder de la democracia o la democracia al poder? Buenos Aires: Siglo XXI, 2006. p. 65-114.

CANELO, Paula. Construyendo elites dirigentes. Los gobernadores provinciales durante la última dictadura militar (Argentina, 1976-1983). Anuario del Centro de Estudios Históricos, v. 11, n. 11, p. 323-341, 2011.

CANELO, Paula. La importancia del nivel municipal para la última dictadura militar argentina. Un estudio a través de sus documentos reservados y secretos (1976-1983). Historia, v. 2, n. 48, p. 405-434, 2015.

CANELO, Paula. La política secreta de la última dictadura argentina (1976-1983). Buenos Aires: Edhasa, 2016.

CANELO, Paula; FRANCO, Marina; MANZANO, Valeria. Introducción. Dossier Dictadura y Estado: la conflictiva y nunca acabada construcción de un campo de estudios. Papeles de Trabajo, v. 10, n. 17, p. 13-28, 2016.

CARRIZO, Gabriel; MORONI, Marisa A.; CAMINO VELA, Francisco. La transición a la democracia. Algunas consideraciones teórico metodológicas. In: CAMINO VELA, Francisco; CARRIZO, Gabriel; MORONI, Marisa A. (coord.). Las transiciones a la democracia en sus actores. Reflexiones desde la Patagonia Rosario:

Prohistoria, 2019. p. 13-29. 
DAMILL, Mario. La economía y la política económica: del viejo al nuevo endeudamiento. In: SURIANO, Juan (dir.). Nueva historia Argentina. Dictadura y democracia 1976-2001. Buenos Aires: Sudamericana, 2005. p. 154-224.

DIARIO LA ARENA. Santa Rosa: [s. l.], 1933-.

DIARIO LA REFORMA. General Pico: [s. l.], 1923-.

FAVARO, Orietta; IUORNO, Graciela (ed.). El “arcón” de la historia reciente en la Norpatagonia argentina. Articulaciones de poder, actores y espacios de conflicto, 1983-2003. Buenos Aires: Biblos, 2010.

FELD, Claudia; FRANCO, Marina (ed.). Democracia hora cero. Actores, prácticas y debates en los inicios de la posdictadura. Buenos Aires: FCE, 2015.

FERRARI, Marcela; GORDILLO, Mónica (comp.). La reconstrucción democrática en clave provincial. Rosario: Prohistoria, 2015.

FERRARI, Marcela; MELLADO, Virginia. La renovación peronista. Organización partidaria, liderazgos y dirigentes. Buenos Aires: Ed. UNTREF, 2016.

FRANCO, Marina. La teoría de los dos demonios en la primera posdictadura. In: FELD, Claudia; FRANCO, Marina (ed.). Democracia hora cero. Actores, prácticas y debates en los inicios de la posdictadura. Buenos Aires: FCE, 2015. p. 23-80.

FRANCO, Marina. La "transición" argentina como objeto historiográfico y como problema histórico. Ayer, v. 107, n. 3, p. 125-152, 2017.

FRANCO, Marina. La última dictadura argentina en el centro de los debates y las tensiones historiográficas recientes. Tempo e Argumento, v. 10, n. 23, p. 138-166, 2018a.

FRANCO, Marina. La defección política y la denuncia sobre los derechos humanos en la última dictadura argentina. Izquierdas, n. 39, p. 229-251, 2018b.

FRANCO, Marina. El final del silencio. Dictadura, sociedad y derechos humanos en la transición (Argentina, 1979-1983). Buenos Aires: FCE, 2018c.

FRANCO, Marina. El 'Documento Final' y las demandas en torno a los desaparecidos en la última etapa de la dictadura militar argentina. Antiteses, v. 11, n. 21, p. 244-266, 2018d.

GARGARELLA, Roberto; MURILLO, María Victoria; PECHENY, Mario (comp.).

Discutir Alfonsín. Buenos Aires: Siglo XXI, 2010. 
GONZÁLEZ BOMBAL, Inés. El Diálogo político. La transición que no fue. Buenos Aires: CEDES, 1991. (Documento CEDES No. 61).

LLUCH, Andrea; DI LISCIA, María Silvia (ed.). Historia de La Pampa. Sociedad, política y economía de la crisis del treinta al inicio del nuevo siglo. Santa Rosa: Ed. UNLPam, 2011. v. 2.

\section{LLUCH, Andrea; SALOMÓN TARQUINI, Claudia (ed.). Historia de La Pampa.}

Sociedad, política y economía de los poblamientos iniciales hasta la provincialización (ca. 8000 AP a 1952). 2. ed. Santa Rosa: Ed. UNLPam, 2014. v. 1.

LVOVICH, Daniel. Sistema político y actitudes sociales en la legitimación de la dictadura militar Argentina (1976-1983). Ayer, v. 75, n. 3, p. 275-299, 2009.

LVOVICH, Daniel. Burócratas, amigos, ideólogos y vecinalistas: el reclutamiento de funcionaros municipales de Morón durante la Dictadura Militar (1976-1983). In: BOHOSLAVSKY, Ernesto; SOPRANO, Germán (ed.). Un Estado con rostro humano. Funcionarios e instituciones estatales en Argentina (desde 1880 a la actualidad). Buenos Aires: UNGS/Prometeo, 2010. p. 411-430.

MANSILLA, César. Las fuerzas de centro. Buenos Aires: Centro Editor de América Latina, 1983.

MAZZEI, Daniel. Reflexiones sobre la transición democrática argentina. PolHis, v. 4, n. 7, p. 8-15, 2011.

MORONI, Marisa A. (comp.). Actores políticos y reorganización partidaria en la Patagonia (1980-1983). Santa Rosa: Ed. UNLPam, 2019.

QUIROGA, Hugo. El tiempo del "Proceso". Conflictos y coincidencias entre políticos y militares 1976-1983. Santa Fe: Homo Sapiens, 2004.

QUIROGA, Hugo. La reconstrucción de la democracia argentina. In: SURIANO, Juan. Nueva Historia Argentina. Dictadura y democracia 1976-2001. Buenos Aires: Sudamericana, 2005. p. 87-155.

RUFFINI, Martha. La pervivencia de la República posible en los territorios nacionales. Poder y ciudadanía en Río Negro. Buenos Aires: Ed. Universidad Nacional de Quilmes, 2007.

SCATIZZA, Pablo. Un Comahue violento. Buenos Aires: Prometeo, 2016.

VELÁZQUEZ RAMÍREZ, Adrián. De la concertación a la multipartidaria: el espacio político partidario en los albores de la transición a la democracia en la Argentina (1983-1987). Revista Contemporánea, v. 7, p. 1-28, 2015. 
VEZZETTI, Hugo. Pasado y presente. Guerra, dictadura y sociedad en la Argentina. Buenos Aires: Siglo XXI, 2002.

YANNUZZI, María de los Ángeles. Autoritarismo, democracia y neoconservadurismo. La cultura política argentina al fin del milenio. IH, n. 19, p. 239-257, 1999. 